\section{Criminalidade e Turismo em São Paulo, Brasil: a violência registrada junto aos turistas estrangeiros}

Criminality and Tourism in the City of São Paulo, Brazil: registered violence against foreign tourists

\section{Henrique Catai Mirian Rejowski}

ABSTRACT: Descriptive-exploratory research about violence and tourism detaching, in such a context, the implications of criminality against foreign tourists in Brazil, more specifically in the city of São Paulo. In some surveys presented by other researchers, it was observed that violence contributes in a negative way for the demand of a touristic destination. The research done by DEATUR - Tourism Police Department - in the city of São Paulo (Brazil), during the period of 1995 to 2000, shows that the foreign tourist is not the major "target" of local criminality; the analysed occurrences describe mugging and theft with major emphasis on the latter and there was no register of homicide involving foreign tourists

KEYWORDS: tourism and violence; criminality; foreign tourists; occurrences and implications; São Paulo (the city and the state); Brazil.

\section{Introdução}

RESUMO: Pesquisa exploratório-descritiva sobre violência e turismo, destacando, nesse contexto, as implicações da criminalidade junto a turistas estrangeiros no Brasil, especificamente no município de São Paulo. Em estudos apresentados por outros pesquisadores, observou-se que a violência contribui negativamente para a demanda de uma localidade turística. Na pesquisa junto à EATUR - Delegacia do Turista - no município de São Paulo (Brasil), compreendendo o período de 1995 a 2000, verificou-se que o turista estrangeiro não constitui o "alvo" preferencial da criminalidade local; as ocorrências analisadas descrevem roubos e furtos, com maior incidência na última modalidade de crime; e não houve o registro de nenhum homicídio envolvendo um turista estrangeiro.

PALAVRAS-CHAVE: turismo e violência; criminalidade; turistas estrangeiros; ocorrências e implicações; São Paulo (cidade e Estado); Brasil.

1. Graduado em Turismo pela Universidade Anhembi Morumbi e em Letras pela Universidade de São Paulo; mestre em Turismo e Lazer pela ECA-USP. Professor em cursos de Turismo e Hotelaria. Contato: Rua Maria Antônia, 267/74 - 01222-010 - São Paulo - SP; e-mail: hcatai@yahoo.com.br.

2. Bacharel em Turismo pela Escola de Comunicações e Artes da Universidade de São Paulo - ECAUSP; livre-docente em Teoria do Turismo e do Lazer pela ECA-USP; professora titular do mestrado em Turismo da Universidade de Caxias do Sul; colaboradora na ECA-USP. Contato: Rua Francisco Getúlio Vargas, 1.130, Cidade Universitária, Bloco 46 - 95070-560 - Caxias do Sul, RS; e-mail mrejowski@ucs.br.
O turismo constitui uma atividade extremamente dependente dos serviços existentes no local a ser visitado, onde a falta de infra-estrutura pode dificultar ou até prejudicar o fluxo de visitantes e, conseqüentemente, determinar a decadência de uma localidade como destino turístico (Beni, 2001). Além disso, o turismo é influenciado por fatores inerentes à composição da sociedade, dentre os quais a violência. Casos de violência em uma localidade podem afetar diretamente a sua procura como destino turístico, pois, como afirma Santana (2001: 268), “independentemente dos muitos atributos que compõem a experiência e as motivações turísticas, a segurança é sem dúvida um dos fatores mais importantes".

Em países da Europa e nos Estados Unidos, a pesquisa voltada à violência tem recebido a contribuição de muitos pesquisadores e profissionais de diversas áreas. No Brasil, apesar dos problemas resultantes do número de crimes apresentados pelas estatísticas, a criminalidade contra turistas ainda não possui estudos aprofundados.

Este artigo é resultado dos estudos desenvolvidos na dissertação de mestrado (Catai, 2004). Ele está estruturado em três partes, além desta Introdução: a apresentação da metodologia desenvolvida para o levantamento das informações junto à DEATUR, um levantamento teórico abordando a relação entre violência e turismo, os resultados da pesquisa e uma análise dos mesmos com base nos estudos anteriores. 
XAVIER, H. 2002. Educação Ambiental: caminho para a sustentabilidade ecológica no turis mo.In: BARRETO, M. \& TAMANINI, E. (Orgs.). Redescobrindo a ecologia no turismo. Caxias do Sul: EDUCS. p. 71-91.

\section{Recebido em 16/10/2004.}

Aprovado em 03/11/2004.

\section{Anexos}

Tabela 1. Fatores que influem na Capacidade de Manejo (cm)

\begin{tabular}{llcc}
\hline Categoria & Fatores que influenciam & Atual & Necessário \\
\hline & água potável & 1 & 2 \\
& placas instrutivas & 0 & 4 \\
& placas informativas & 0 & 2 \\
& placas de sinalização & 0 & 2 \\
& lixeiras & 2 & 3 \\
& sanitários & 2 & 2 \\
& telefone & 1 & 2 \\
& primeiros socorros & 1 & 1 \\
\hline \multirow{2}{*}{ Pessoal } & administrador & 1 & 1 \\
& base & 3 & 3 \\
& monitores credenciados & 32 & 32 \\
& guarda florestal & 22 & 22 \\
\hline \multirow{2}{*}{ Manutenção } & corrimão (construção) & 1 & 1 \\
& escada (construção) & 1 & 1 \\
& ponte (construção) & 0 & 1 \\
& podas em árvores & 3 & 3 \\
\hline \multirow{2}{*}{ Total } & & 70 & 82 \\
\hline
\end{tabular}

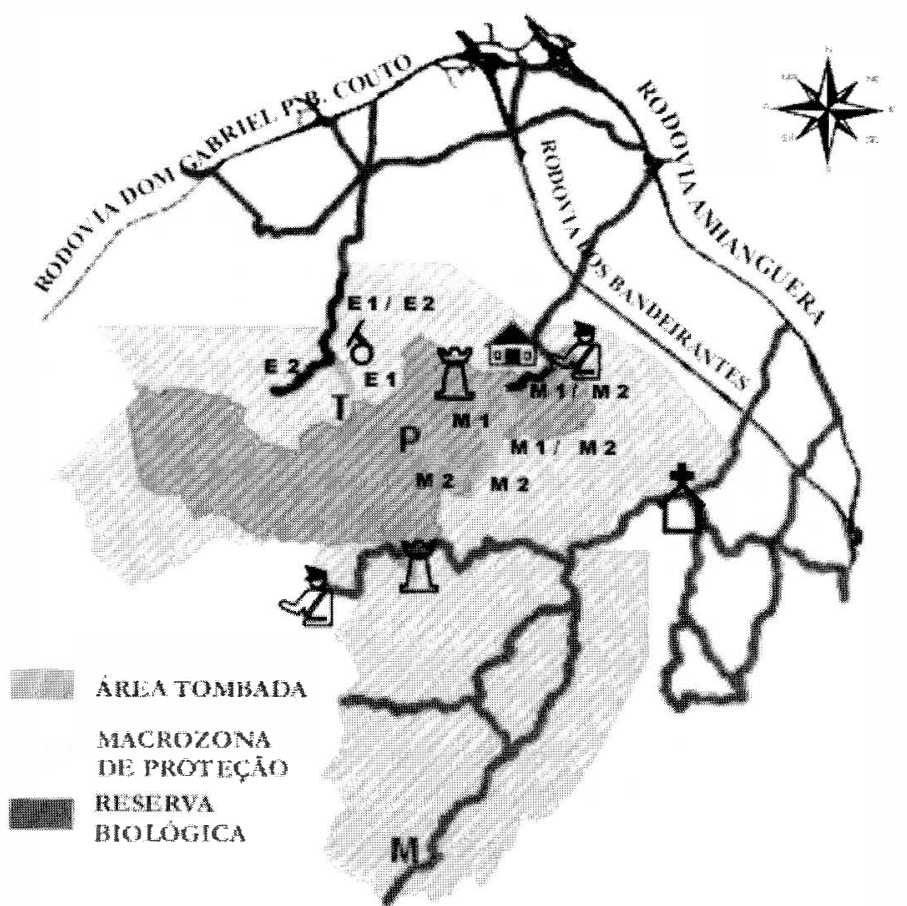

20 Trilhas - Acesso depende de autorizsę̆

211: Estradas Municipais - Acesso depende de autorizacáo

1:- Estradas Municipais - Acesso independe de autorìnação

\section{ESTRADAS E TRILHAS LICENCIADAS}

E1 : Região da Ermida - Trial

E2 : Regiảo da Ermida - Jardirn Serra da Emida

M1: Regiăo da Malota Mirante

M2: Regián da Maleta - Paraiso

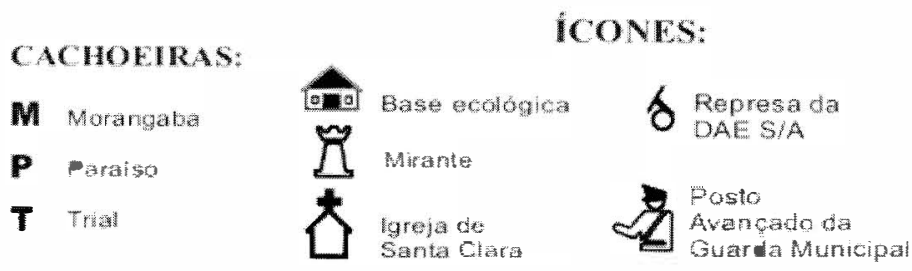

Fonte: Prefeitura Municipal de Jundiaí, Secretaria de Planejamento e Meio Ambiente. Disponível em: <http://www.jundiai.sp.gov.br/planejamento/serra.htm>. Acesso em: 16 mar. 2004.

Figura 1. Mapa específico da Serra do Japi 


\section{Metodologia}

A primeira parte da pesquisa aqui apresentada constitui um levantamento bibliográfico cruzando os temas violência, criminalidade, turismo e demanda. As informações referentes aos crimes envolvendo turistas estrangeiros tiveram como fonte a Delegacia do Turista - DEATUR, sediada no município de São Paulo, e atualmente denominada Divisão Policial de Portos, Aeroportos, Proteção ao Turista e Dignitário.

Apesar de definido o período de 1990 a 2000, os dados da DEATUR só foram arquivados por cinco anos, razão pela qual a análise dos Boletins de Ocorrência (BOs) se restringiu ao período de 1995 a 2000.

Esclareça-se que essa delegacia não atende somente às ocorrências com estrangeiros. Além disso, a Divisão de Estatística, órgão da Secretaria Estadual de Segurança responsável pela realização da pesquisas relacionadas aos crimes cometidos, não faz distinção entre turistas e residentes, apenas quanto à natureza das ocorrências: furto, roubo, estelionato e outros. ${ }^{3}$

A coleta de dados foi efetuada com base na observação de cada во registrado desde janeiro de 1995 a dezembro de 2000, e realizada nos dias 22 e 23 de janeiro de 2003, contando com as seguintes dificuldades:

- não existe um trabalho estatístico abordando o tema violência e turismo nos órgãos de governo;

- os registros atuais são enviados diretamente para um banco de dados; todavia, não existe nenhum campo de preenchimento que diferencie o morador do turista, ou sexo e idade das vítimas; о во é preenchido com dados sobre residência e nacionalidade, natureza da ocorrência, local da ocorrência, descrição do evento e os bens usurpados;

- nem sempre os Bos são enviados à sede da DEATUR, localizada na Rua São Bento (centro de São Paulo). Apenas seus dados são registrados;

- a DEATUR não atende apenas turistas. Conseqüentemente, há a necessidade do levantamento de cada BO, visto que as queixas podem ser de cidadãos moradores do município de São Paulo ou de qualquer outra localidade.

Esclareça-se, ainda, que o turista, além de se reportar à DEATUR, pode ser atendido em qualquer outro Distrito Policial. Com isso, os dados dos DPs acabam

3. Esses mesmos dados são repassados ao SEADE, que os publica em seu Anuário Estatístico do Estado de São Paulo. contabilizando o total de ocorrências envolvendo turista no período de 1995 2000. Aqui, porém, serão considerados apenas os Bos oriundos das delegacias localizadas na Rua São Luiz (centro de São Paulo) e no Aeroporto de Congonhas, por serem as que registram o maior número de ocorrências de crimes envolvendo turistas estrangeiros.

Foram desconsiderados os casos nos quais a ocorrência de crime não foi na cidade de São Paulo ${ }^{4}$. A Tabela 1 apresenta a quantidade de Bos selecionados e levantados no período.

Tabela 1. Boletins de Ocorrência - 1995 a 2000

\begin{tabular}{|c|c|c|}
\hline ANO & $\begin{array}{c}\text { Boletins de Ocorrência } \\
\text { LEVANTADOS }\end{array}$ & $\begin{array}{c}\text { Boletins de Ocorrência } \\
\text { SELECIONADOS }\end{array}$ \\
\hline 1995 & 170 & 166 \\
\hline 1996 & 146 & 145 \\
\hline 1997 & 63 & 63 \\
\hline 1998 & 429 & 427 \\
\hline 1999 & 303 & 300 \\
\hline 2000 & 420 & 419 \\
\hline
\end{tabular}

Para o registro dos dados desses Bos, utilizou-se uma planilha (Figura 1) com campos referentes ao local de residência dos turistas e à natureza dos crimes cometidos contra eles. Quanto à natureza, a primeira coluna refere-se às ocorrências de furto, roubo ou estelionato; a segunda, aos casos de homicídio, não fazendo uma diferenciação entre doloso ou culposo; e a terceira, a ocorrências diversas (outros): perigo de vida ou saúde; extravio de documentos; preservação de direitos; dano; uso de documento falso; apreensão de veículos; receptação dolosa; lesão corporal dolosa; contrabando; incêndio; injúria; violação de bagagem; invasão de área restrita; desinteligência; veículo localizado; extravio de mercadoria; porte ilegal de armas; desaparecimento de pessoas; apreensão de crachás e convites; crimes contra as relações de consumo; violação de direito autoral.

4. Muitos turistas vitimados em outras localidades registram a ocorrência em São Paulo, como, po exemplo, o estrangeiro que, furtado em Curitiba, registrou a ocorrência quando estava no aeroporto de Congonhas. 


\begin{tabular}{|c|c|c|c|c|}
\hline \multicolumn{5}{|c|}{ Mês/Ano: } \\
\hline & \multicolumn{4}{|l|}{ NATUREZA DO CRIME } \\
\hline VÍTIMA & Furto/Roubo/Estelionato & Homicídio & Outros & Total \\
\hline \multicolumn{5}{|l|}{$\begin{array}{l}\text { Morador do } \\
\text { Município }\end{array}$} \\
\hline \multicolumn{5}{|l|}{$\begin{array}{l}\text { Turista } \\
\text { doméstico }\end{array}$} \\
\hline \multicolumn{5}{|l|}{$\begin{array}{l}\text { Turista } \\
\text { Internacional }\end{array}$} \\
\hline Total & & & & \\
\hline
\end{tabular}

Figura 1. Planilha - Ocorrência de crimes em São Paulo - 1995-2000

Quanto ao local de residência, a separação bruta das vítimas faz referência a três grandes grupos: morador do município ou da Grande São Paulo ${ }^{5}$, turista doméstico e turista internacional. Para efeito de separação desses três tipos, considerou-se o local de residência que a vítima citava no BO, e não apenas a nacionalidade. Foram considerados turistas domésticos as vítimas que residem no Brasil, mas fora do município de São Paulo e da Grande São Paulo; e como turistas internacionais, as residentes em países estrangeiros.

O enorme leque semântico das explicações a respeito de furto, roubo, homicídio e crime podem levar a problemas de caracterização dos delitos na pesquisa. A definição jurídica para crime é "como sendo o fato típico e antijurídico" (Führer e Führer, 2001: 24). Além disso, o crime pode ser de dolo ou de culpa. No primeiro caso, o agente tem o propósito de praticar o fato: "crimes dolosos são os crimes

5. Os municípios que compreendem a Grande São Paulo foram determinados pela mesma metodologia utilizada pelo SEADE e inclui Diadema, São Bernardo do Campo, Mauá, São Caetano, Osasco, Guarulhos, Santa Isabel, Arujá, Guararema, Mogi das Cruzes, Biritiba Mirim, Salesópolis, Suzano, Rio Grande da Serra, Santo André, Diadema, Juquitiba, São Lourenço, Embu-Guaçu, Itapecerica da Serra, Cotia, Embu, Taboão da Serra, Itapevi, Vargem Grande Paulista, Carapicuíba, Barueri, Santana de Parnaíba, Pirapora de Bom Jesus, Cajamar, Franco da Rocha, Francisco Morato e Mairiporã. intencionais" (Führer e Führer, 2001: 33). Já no crime com culpa não há a intenção do delito, sendo que a culpa pode ser por negligência, imprudência ou imperícia.

A pesquisa centra-se nos crimes contra o patrimônio e contra a pessoa, pois estes, conforme demonstram estudos de Ryan (1993), Albuquerque e McElroy (2002), são os mais propensos a ocorrer com turistas estrangeiros.

\section{Violência e turismo - Uma breve refłexão}

A violência pode ter efeitos devastadores na economia de uma localidade, dentre os quais Pizam et al. (1997) elencaram quatro: aumento dos gastos na comunidade com a segurança na época de férias, despesas relativas aos roubos e danos ocorridos com residentes e turistas, aumento no clima de tensão entre moradores e turistas e, por último, nem sempre a presença da lei poderá ser considerada como aspecto de segurança.

Para Pizam et al. (1997: 25), o turista escolhe um destino não apenas com base no preço ou na imagem, mas também se valendo da questão da segurança e proteção pessoal. Na visão desses pesquisadores, o turista constitui um alvo fácil para as atividades criminosas pelos seguintes fatores:

- é um alvo tentador, pois traz consigo dinheiro em grande quantidade e outros objetos;

- possui comportamento de risco, como saídas noturnas, viagem para locais ermos, consumo de bebidas e outras drogas;

- encontra-se deslocado dos grupos sociais em que vive;

- não conhece a língua;

- em alguns casos, são considerados agressivos e não cumpridores das regras locais;

- a percepção de segurança é do país de origem e das leis aplicadas onde mora, o que, em geral, é diferente das leis do lugar que está visitando.

Os estudos de Pizam et al. (1997) e Ryan (1993) comprovam a complexidade de se analisar o problema da violência quando relacionado ao turismo. As variantes geográficas, a gravidade dos atos, o poder de penetração na mídia são questões a serem consideradas em abordagens sobre o tema.

A perspectiva que considera o turista um alvo em potencial da criminalidade citadina deve ser ponderada, visto que nem todos os crimes têm como foco o visitante. Ryan (1993), em seu estudo sobre a relação intrínseca entre crime, violência, terrorismo e turismo, determinou os tipos de violência em que o turista pode se envolver e os locais de sua ocorrência. Para o autor, essa relação sofre 
variações que vão de crimes em que o turista é um alvo acidental até o outro extremo, em que o turista é efetivamente o objeto do ato terrorista. Sua divisão está categorizada em cinco tipos:

- Tipo 1: o turista é uma vítima da ação criminal que ocorre independentemente da natureza turística do destino; a maioria dos crimes é contra a população local.

- Tipo 2: os turistas não são necessariamente as vítimas principais, mas os locais de ocorrência constituem atração turística; nesse sentido, o autor cita regiões da América do Sul.

- Tipo 3: o lugar atrai atividades criminais por causa do trânsito de turistas, e estes se constituem em vítimas fáceis; nesses locais, porém, o turista também pode ser o agressor, tanto do meio ambiente como dos costumes, e até moral e fisicamente. O crime, nesse caso, é desorganizado, sendo majoritariamente cometido por indivíduos ou pequenos grupos, além de serem crimes básicos e com o objetivo de conseguir algum bem. Ryan (1993) cita a cidade de Honolulu, em específico.

- Tipo 4: as atividades criminais tornam-se organizadas para atingir certos tipos de demanda turística; neste caso, Ryan (1993) cita o caso de Cancún.

- Tipo 5: organizações criminais e grupos terroristas cometem ações violentas e específicas contra o turista e os locais turísticos.

No estudo de Albuquerque e McElroy (2002), os autores apresentam resultados interessantes sobre a criminalidade em Barbados (Caribe), entre os anos de 1990 e 1993. Partindo de uma tipologia envolvendo os turistas, observaram e revelaram que esse segmento era vítima mais freqüente de crimes do que os residentes; contudo, os turistas sofriam com os delitos oriundos de roubos e furtos, enquanto os residentes tinham maior possibilidade de serem vítimas de delitos violentos - homicídio.

Outro fato detectado por Albuquerque e McElroy (2002) diz respeito à nãocoleta de informação quanto à origem da vítima em muitos países, e isso se deve possivelmente à preocupação de que esses dados se difundam negativamente $\mathrm{e}$ gerem uma propaganda adversa. Com base nos dados da Royal Police Force Barbados (Caribe), que prepara informes e quantifica os delitos contra os turistas, os autores observam que, entre 1989 e 1993, nenhum turista foi assassinado, havendo somente agressões e assaltos com agravantes. Essa pesquisa de Albuquerque e McElroy (2002) também demonstrou que os turistas são vítimas de delitos contra a propriedade e de roubo, que geralmente se relacionam ao furto de objetos - carteira, bolsas, etc. - nos locais próximos de onde estão hospedados e de seus veículos estacionados, conforme a Tabela 2 :

\begin{tabular}{|c|c|c|c|c|c|c|c|c|c|c|}
\hline 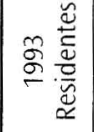 & ${ }^{12}=$ & $\begin{array}{l}\bar{\infty} \\
\stackrel{\infty}{\sim}\end{array}$ & \begin{tabular}{l}
\multirow{j}{0}{} \\
d.
\end{tabular} & $\stackrel{m}{\stackrel{\sim}{\sim}}$ & 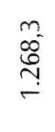 & $\begin{array}{l}\infty \\
\stackrel{\infty}{\Phi} \\
\stackrel{\Phi}{\infty}\end{array}$ & $\tilde{g}^{2}$ & $\begin{array}{l}\stackrel{\mathfrak{Z}}{\forall} \\
\stackrel{f}{2}\end{array}$ & $\frac{\pi}{z}$ & 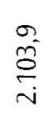 \\
\hline 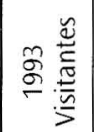 & 0 & $\begin{array}{l}\infty \\
\mathbb{N}\end{array}$ & $\begin{array}{l}\stackrel{N}{*} \\
\vec{m}\end{array}$ & $\begin{array}{l}0 \\
\text { of } \\
\text { s. }\end{array}$ & 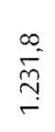 & 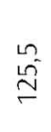 & $\begin{array}{l}\infty \\
\stackrel{亏}{\circ}\end{array}$ & $\begin{array}{l}\infty \\
\stackrel{\infty}{0} \\
\stackrel{\rho}{N}\end{array}$ & $\frac{n}{8}$ & $\underset{i}{\stackrel{g}{E}}$ \\
\hline 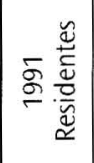 & $\stackrel{m}{n}$ & $\begin{array}{l}\tilde{N} \\
\tilde{c}\end{array}$ & $\begin{array}{l}\text { Na } \\
\stackrel{m}{n}\end{array}$ & $\begin{array}{l}\infty \\
\stackrel{\infty}{N}\end{array}$ & $\begin{array}{l}\text { ñ } \\
\text { ऊ̂ }\end{array}$ & $\begin{array}{l}\text { Lे } \\
\text { J్ }\end{array}$ & $\begin{array}{l}0 \\
\stackrel{0}{0} \\
\simeq\end{array}$ & 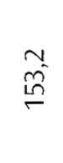 & $\Sigma$ & $\begin{array}{l}\infty \\
\infty \\
\infty \\
\infty \\
\stackrel{\infty}{+}\end{array}$ \\
\hline 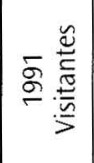 & 0 & बें & $\begin{array}{l}0 \\
\dot{f}\end{array}$ & $\begin{array}{l}\stackrel{0}{r} \\
\stackrel{m}{r}\end{array}$ & $\underset{\substack{n \\
\hat{\sigma}}}{\stackrel{n}{-}}$ & ז. & 今े & $\begin{array}{l}\stackrel{0}{+} \\
\stackrel{d}{N}\end{array}$ & $\stackrel{m}{\stackrel{m}{N}}$ & $\frac{\sigma}{\sigma}$ \\
\hline 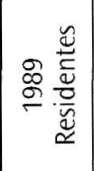 & $\sigma_{\hat{~}}$ & $\begin{array}{l}\text { o. } \\
\stackrel{+}{0}\end{array}$ & $\begin{array}{l}0 \\
\dot{\sim}\end{array}$ & $\begin{array}{l}\text { के } \\
\overbrace{n}^{\circ}\end{array}$ & $\stackrel{N}{\stackrel{N}{\infty}}$ & $\stackrel{\stackrel{n}{n}}{\stackrel{n}{N}}$ & $\underset{\infty}{\stackrel{\infty}{\infty}}$ & 点 & $\frac{\pi}{z}$ & 席 \\
\hline 怘 & 0 & $\hat{m}^{m}$ & o & $\frac{m}{m}$ & $\begin{array}{l}0 \\
\stackrel{\Sigma}{\Sigma} \\
\dot{i}\end{array}$ & $\begin{array}{l}\frac{t}{6} \\
\frac{\omega}{6}\end{array}$ & $\frac{0}{\hat{6}}$ & $\begin{array}{l}\text { जे } \\
\stackrel{N}{N} \\
\text { in }\end{array}$ & $\bar{\sigma}$ & $\begin{array}{l}\stackrel{n}{\tilde{I}} \\
\stackrel{0}{0} \\
0\end{array}$ \\
\hline$\stackrel{\swarrow}{ٍ ٍ ~}$ & 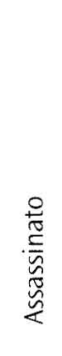 & 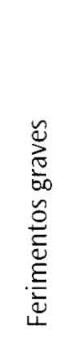 & 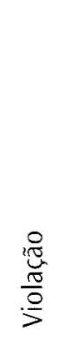 & $\stackrel{\circ}{\stackrel{0}{z}}$ & 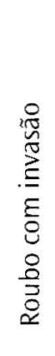 & 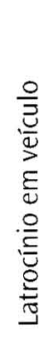 & 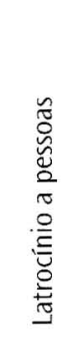 & 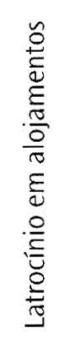 & 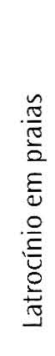 & 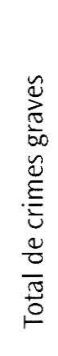 \\
\hline 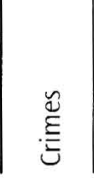 & & 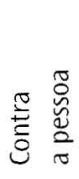 & & & & & 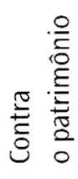 & & & \\
\hline
\end{tabular}


Apesar da relevância de tais dados para o turismo no Caribe, especificamente em Barbados, as autoridades policiais e políticas não realizam estudos para detectar a violência contra turistas, por exemplo, em locais e dias da semana mais prováveis. Albuquerque e McElroy (2002: 362) consideram ainda que tal "lacuna não é exclusiva do Caribe. Muitos destinos não distinguem geralmente os delitos contra os residentes daqueles contra a população visitante".

No caso brasileiro, encontram-se os estudos de Teixeira (1994, 1995, 1996), nos quais o autor analisa, comparativamente, a queda do turismo no Rio de Janeiro e o aumento da criminalidade, especificamente dos homicídios. Essa visão deverá receber uma análise criteriosa, pois a mera comparação de que o aumento da violência pode refletir diretamente na queda do turismo tem o mesmo teor de simplicidade que a comparação entre crescimento do desemprego e aumento da criminalidade.

Partindo desses estudos, observou-se que o turismo pode sofrer influências negativas devido aos problemas de violência, sendo que tal relação pode variar dependendo da localidade ou do tipo de ato violento. Assim, torna-se pertinente verificar junto a uma cidade brasileira, no caso São Paulo, como ocorre a relação turismo e violência.

\section{Crimes contra turistas - A violência entre 1995 e 2000}

Os dados coletados nos Bos no período de 1995 a 2000 são analisados conjuntamente no texto a seguir, com base na Figura 2. Considerando que os Bos não são necessariamente registrados no local do crime, ressalta-se que as ocorrências envolvendo turistas estrangeiros estão concentradas, em sua maior parte, no centro da capital de São Paulo ou no local em que se realiza algum evento na cidade. Parte desse resultado é proveniente das limitações da pesquisa, que analisou os casos registrados na DEATUR.

De grande relevância foi o resultado referente à natureza dos crimes. Os BOs concentram um número maior de furtos e roubos, com reduzida incidência de estelionatos e nenhum homicídio, sendo que os furtos são geralmente de mochilas, máquinas fotográficas e passaporte. A semelhança de dados ocorre quando se estabelece uma comparação com a pesquisa de Albuquerque e McElroy (2002). $\mathrm{Na}$ localidade pesquisada pelos autores, a maior parte dos turistas sofre furtos e roubos. Nesse sentido, o resultado demonstra uma certeza na metodologia da pesquisa e aponta caminhos para uma política de prevenção, fato que já ocorre em outros países. No aeroporto de Congonhas são raros os furtos e roubos contra turistas estrangeiros, possivelmente pelo mesmo se constituir um aeroporto regional onde prepondera a chamada ponte aérea Rio - São Paulo.
Outra questão a ser ressaltada é a de que o roubo com agressão não foi preponderante, somando cerca de cinco casos. Esse resultado aponta uma contradição quanto ao clima de insegurança apresentado aos turistas, pois a violência não está presente de maneira pessoal ou exclusiva em relação a eles.

No período pesquisado não houve um único caso de homicídio envolvendo turistas estrangeiros, outro item que traduz o pequeno risco de um turista sofrer uma agressão física. Independentemente das altas taxas de homicídio, estas não atingem diretamente o visitante estrangeiro. Dessa maneira, quando empresas de segurança apresentam o município de São Paulo como de grande perigo e semelhante a cidades de países como Colômbia e Egito, essas firmas também omitem que a probabilidade de um turista ser assassinado é pequena.

Com referência aos crimes elencados na coluna "natureza/outros", a maioria dos incidentes envolve o extravio de documentos, obrigando o turista a comunicar o ocorrido e a apresentar o Bo na saída do País.

A preocupação do turista ao fazer $\mathrm{O}$ BО também reside no registro oficial para solicitação de seguro no seu país de origem. Antes da viagem, as agências oferecem o seguro para diversas ocorrências que possam eventualmente acontecer. Nesse caso, о во constitui um documento oficial para o pagamento do prejuízo.

Outro fator que pode interferir no resultado diz respeito à possibilidade de ser inverídico o fato de o turista haver sofrido roubo ou furto. Pensando que a perda por distração de um bem não poderá ser registrada e, conseqüentemente, a solicitação do seguro não será possível, infere-se que há probabilidade de alguns casos serem registrados como furtos mesmo não tendo sido este o caso. Também deve ser lembrado que a dificuldade de registrar a ocorrência somada ao pouco tempo disponível do turista pode levá-lo a não se dirigir a uma delegacia, dependendo do valor extraviado.

Muitos crimes ocorrem em outras regiões do País, mas a queixa é formalizada, em geral, em São Paulo, o que pode interferir nos dados estatísticos totais. Um exemplo foi o caso de um turista furtado em Curitiba e que se deu conta do ocorrido apenas no hotel em São Paulo. Dessa maneira, mesmo que ocorra por parte dos órgãos de segurança a contabilização de crimes envolvendo visitantes, haverá também a necessidade de especificar a localidade, pois poderá gerar grandes distorções. Acrescente-se aí o dado de que, para o turista, principalmente o estrangeiro, o fato de ser furtado em Curitiba ou em São Paulo não fará diferença quando de seu retorno ao país de origem, lembrando novamente a lei de similitude e simetria exposta por Beni (2001).

Comparando as séries de 1995 a 2000 observa-se uma tendência constante em torno de 10 a 20 Bos por mês (furtos, roubos, estelionatos) envolvendo turistas estrangeiros. Lembrar que esse resultado tem como base os meses de janeiro, mar- 
ço, julho, setembro e dezembro, e que os registros foram fornecidos pela DEATUR. Esse número pode aumentar caso seja feita uma pesquisa em outras delegacias do município de São Paulo. Contudo, essa tendência não demonstra que o turista estrangeiro tornou-se o "alvo" e poderia ser elencado no que Ryan (1993) considera como vítima principal de alguns crimes. Esse fato reflete o crescimento da violência na cidade e, dessa maneira, o turista é tão vítima como qualquer outra pessoa.

Por meio dos dados coletados e organizados pode-se inferir que o turista estrangeiro não forma um grupo diferenciado e com maior probabilidade de sofrer a ação criminosa. O turista no município de São Paulo pode ser elencado no grupo três - tipo de crime definido por Ryan (1997) - devido ao centro ser um espaço de grande movimento de turistas.

Apesar do elevado índice de crimes, principalmente homicídio, a cidade não é um local perigoso nos espaços freqüentados por turistas, como apresentado na análise teórica sobre as áreas de insegurança do município. A maior parte dos turistas freqüenta áreas próximas aos estabelecimentos de hospedagem, restaurantes, casas de espetáculos e espaços de eventos. Tais equipamentos e serviços localizam-se em áreas nobres da cidade, nas quais a taxa-proporção de criminalidade, principalmente homicídio, não atinge números assustadores e, conseqüentemente, reduz a probabilidade de atingir o turista, haja vista que não foi registrado nenhum crime dessa natureza no levantamento dos boletins. Como observado no gráfico (Figura 2), o número de crimes contra o patrimônio envolvendo turistas

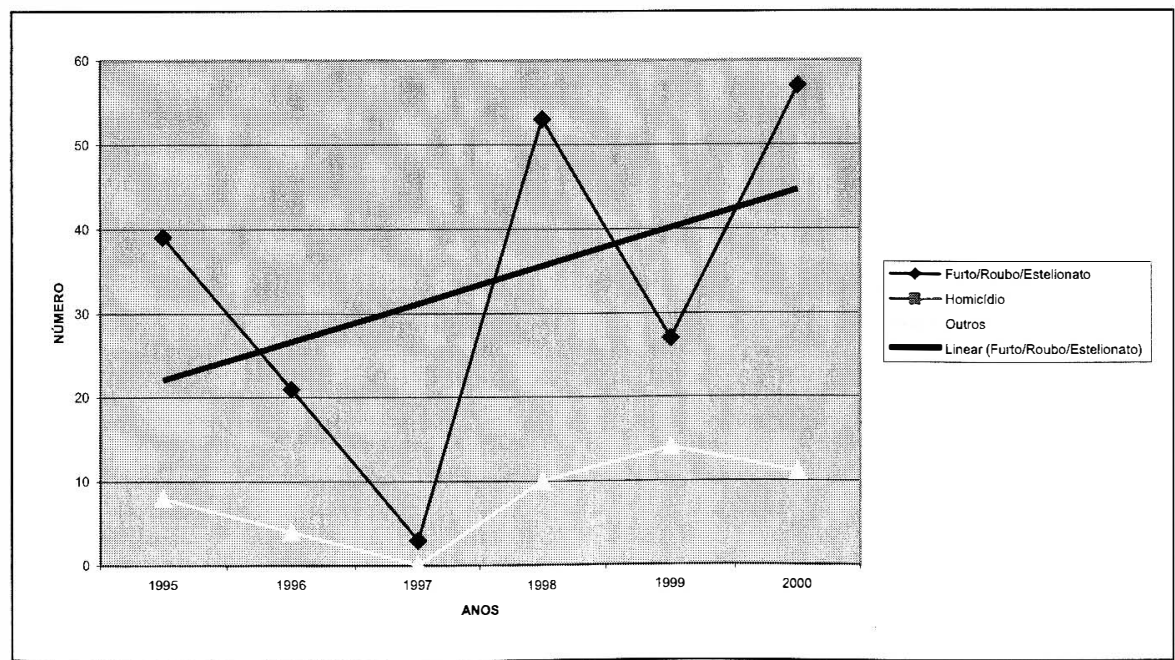

Figura 2. Boletins de ocorrência - Turistas estrangeiros (DEATUR, 1995-2000) Fonte: DEATUR (1995-2000). encontra-se em uma curva de tendência ascendente, e isso pode ser resultado de fatores como aumento do número de turistas que registram crimes; maior conhecimento sobre o atendimento especializado da DEATUR ao turista; maior atenção na organização dos boletins de ocorrência e, conseqüentemente, a compilação dos mesmos torna-se confiável; o fato de os dados acompanharem o crescimento geral da violência na cidade.

\section{Considerações finais}

No campo do turismo, a violência deu origem a vários estudos, principalmente a partir da década de 1990, em consonância com o crescimento de ações terroristas, conflitos locais e a sua própria expansão em diversas partes do mundo. As pesquisas no exterior demonstram que a criminalidade no meio urbano atinge o turista por meio dos crimes de furto e roubo, com reduzidas chances do mesmo sofrer violências graves, como homicídios.

O estudo caracterizou e analisou quais são os crimes que vitimam o turista estrangeiro no município de São Paulo, especificamente na região central. Para isso, efetuou-se o levantamento e a organização dos søs lavrados na DEArUr. A composição desses dados revela que o turista é alvo da criminalidade no que diz respeito a furto, roubo e estelionato, não ocorrendo nenhum caso de homicídio no período analisado (1995 a 2000).

$\mathrm{O}$ resultado da pesquisa permite concluir que o turista dificilmente será alvo de crimes violentos - homicídio -, já que estes não ocorrem com freqüência e em grande quantidade nos locais em que a maior parte dos visitantes estrangeiros circula. O crescimento dos registros de ocorrência envolvendo turistas é reflexo de igual aumento das taxas de violência das cidades brasileiras. Um problema para diagnosticar a violência que envolve o turista é a falta de dados estatísticos organizados provenientes de todas as delegacias da capital do Estado de São Paulo, impossibilitando uma quantificação precisa e comparativa.

Ao finalizar este artigo, apresentam-se as seguintes propostas de estudo e ação futuras:

- aprofundar os estudos teóricos que relacionam a criminalidade ao turismo, com ênfase no Brasil, e estudos comparativos com países do continente latino-americano;

- desenvolver trabalhos que visem a coleta de dados estatísticos mais recentes; 
- elaborar estudos similares a este, tendo como foco outras cidades brasileiras;

- relacionar tipos de crime e origem do turista.

\section{Referências bibliográficas}

ALBUQUERQUE, K. \& MCELROY, J. 2002. Turismo y Delincuencia en el Caribe. Annals of Tourism Research en Español. v. 1, n. 2, p. 356-373.

BENI, M. C. 2001. Análise estrutural do turismo. 4. ed. rev. São Paulo: SENAC.

CATAI, H. 2004. Violência e turismo: criminalidade e suas implicações na demanda turística internacional em Sāo Paulo. Dissertaçāo (Mestrado) - ECA/USP, São Paulo.

CERNICHIARO, R. V. s.d. Dicionário de direito penal. Brasília: Universidade de Brasília.

FRAGOSO, C.H. 1981. Lições de direito penal. Parte Especial. São Paulo: Forense.

FÜHRER, M. C. A. \& FÜHRER, M. R. E. 2001. Resumo de direito penal (Parte Geral) 20. ed. São Paulo: Melhoramentos.

PIZAM, A et al. 1997. Making tourist feel safe: whose responsibility is it? Journal of Travel Research. v. 36, n. 1, p. 23-28.

RYAN, C. 1993. Crime, violence, terrorism and tourism. An accidental or intrinsic relationship? Tourism Management. v. 14, n. 3, p. 173-183, june.

SANTANA, G. 2001. Criminalidad, seguridad y turismo. La imagen de Balneario Camboriu, Brasil, desde la perspectiva de turistas y de residentes. Estudios y Perspectivas en Turismo. v. 10, n. 3 y 4 , p. 267-289.

TEIXEIRA, Ib. 1994. Os dólares que o Brasil perde com a violência. Conjuntura Econômica. Rio de Janeiro, n. 59-61, set.

1995. O colapso do turismo e a violência no Brasil. Conjuntura Econômica. Rio de Janeiro, n. 63-64, dez. 1996. O fantástico colapso do turismo no Brasil. Conjuntura Econômica. Rio de Janeiro, n. 42-43, jan.

Recebido em: 06/04/2005.

Aprovado em: 10/09/2005.

Revista impressa em novembro de 2005. Tiragem: 1.000 exemplares. 